\title{
Rituximab therapy for chonic and refractory immune thrombocytopenic purpura: a long-term follow-up analysis
}

\author{
Jaime Garcia-Chavez • Abraham Majluf-Cruz • \\ Laura Montiel-Cervantes • \\ Miriam García-Ruiz Esparza • Jorge Vela-Ojeda • \\ The Mexican Hematology Study Group
}

Received: 29 January 2007 / Accepted: 7 May 2007 / Published online: 14 September 2007

(C) Springer-Verlag 2007

\begin{abstract}
The aim of this study was to evaluate the longterm response to rituximab in patients with chronic and refractory immune thrombocytopenic purpura (ITP). Adults with ITP fail to respond to conventional therapies in almost $30 \%$ of cases, developing a refractory disease. Rituximab has been successfully used in these patients. We used rituximab at $375 \mathrm{mg} / \mathrm{m}^{2}$, IV, weekly for a total of four doses in 18 adult patients. Complete remission (CR) was considered if the platelet count was $>100 \times 10^{9} / 1$, partial remission (PR) if platelets were $>50 \times 10^{9} / 1$, minimal response (MR) if the platelet count was $>30 \times 10^{9} / 1$ and $<50 \times 10^{9} / 1$, and no response if platelet count remained unchanged. Response was classified as sustained (SR) when it was stable for a minimum of 6 months. Median age was 43.5 years (range, 17 to 70 ). Median platelet count at baseline was $12.5 \times 10^{9} / 1$ (range, 3.0 to 26.3 ). CR was achieved in five patients (28\%), PR in five (28\%), MR in four $(22 \%)$, and two patients were classified as therapeutic failures (11\%). Two additional patients were lost to followup. The median time between rituximab therapy and response was 14 weeks (range, 4 to 32). SR was achieved in 12 patients $(67 \%)$. There were no severe adverse events during rituximab therapy. During follow-up (median, 26 months; range, 12 to 59), no other immunosuppressive
\end{abstract}

J. Garcia-Chavez $\cdot$ L. Montiel-Cervantes $\cdot$ M. G.-R. Esparza •

J. Vela-Ojeda

Departamento de Hematología, UMAE "Dr. Antonio Fraga

Mouret", Hospital de Especialidades CMN "La Raza",

Mexico City, Mexico

A. Majluf-Cruz $(\bowtie)$

Unidad de Investigación Médica en Trombosis, Hemostasia y Aterogénesis, Hospital General Regional Gabriel Mancera, Instituto Mexicano del Seguro Social,

Apartado postal 12-1100, Mexico City, México 12 DF, Mexico

e-mail: amajlufc@gmail.com drugs were used. In conclusion, rituximab therapy is effective and safe in adult patients with chronic and refractory ITP. Overall response rate achieved is high, long term, and with no risk of adverse events.

Keywords Chronic ITP - Rituximab - Anti-CD20 ·

Refractory ITP

\section{Introduction}

In immune thrombocytopenic purpura (ITP), platelets are coated with an IgG autoantibody that prompts its premature destruction and, as a result, different grades of peripheral thrombocytopenia and clinical bleeding become evident [5, 23]. Steroids are the first-line treatment for acute ITP. In case of failure to steroids, splenectomy induces a 70 to $80 \%$ response rate [10]. However, almost $30 \%$ of adults with ITP fail to respond to conventional therapies [steroids, IV immunoglobulin (IVIg), splenectomy, or immunosuppressive drugs] and, eventually, they develop a chronic refractory disease $[5,12,23]$. Refractory patients are defined as those who failed standard-dose steroids and splenectomy, requiring further treatment due to unsafe platelet counts $\left(<30 \times 10^{9} / 1\right)$ or clinical bleeding. These patients are unlikely to be cured, although spontaneous remissions sometimes occur [17]. If a patient becomes refractory, some alternatives are available such as danazol, dapsone, azathioprine, high-dose steroids, or chemotherapy combinations like CHOP regimen. However, these options are not quite useful because if response is achieved it is but for a brief period and sustained responses are scarce [23]. Hematopoietic stem cell transplantation has been occasionally used in some cases, but this option represents a highrisk procedure [14]. At the end, these patients may respond 
poorly to subsequent therapy, may have significant morbidity from the disease and its treatment (bleeding and infections secondary to immunosuppressive therapy), and the mortality rate at 10 years may rise up to $20 \%[5,11]$. On the other hand, these patients have higher hemorrhagic risk imposed by trauma or surgery. Therefore, new treatment strategies for these patients are needed.

Rituximab is an anti-CD20 chimeric murine-human monoclonal antibody. CD20 is a B-lymphocyte membrane protein absent on other normal cells. This monoclonal IgGkappa antibody is used in non-Hodgkin lymphomas because it induces apoptosis or direct lysis of B cells [19]. In ITP, B cells are responsible of autoantibody production and the subsequent platelet opsonization that allows its destruction. Therefore, if B cell clones are eliminated, thrombocytopenia could be reverted.

There are some reports informing that rituximab is useful in refractory ITP showing a high overall response rate, with complete remission (CR) and partial remission (PR) rates ranging from 48 to $54 \%[4,8,9,18,20-22]$. We report herein our long-term experience with rituximab therapy in chronic and refractory ITP.

\section{Materials and methods}

In a 5-year period, we prospectively administered rituximab to all patients with chronic and refractory ITP who were unresponsive to prednisone, azathioprine, vincristine, danazol, and high-dose dexametasone, among other therapies, including those unsuccessfully splenectomized. Patients must have a platelet count of $<30 \times 10^{9} / 1$ to be considered for this therapy.

Rituximab was given in doses of $375 \mathrm{mg} / \mathrm{m}^{2}$, diluted in $500 \mathrm{ml} \mathrm{5 \%}$ dextrose-water solution in a 4-h continuous IV infusion. This regimen was indicated weekly for four doses after prophylactic application of antipyretic and antihistamine premedication administered 30 min before rituximab infusion (paracetamol, $500 \mathrm{mg}$, PO; diphenhydramine, $30 \mathrm{mg}$, PO; and hydrocortisone, $100 \mathrm{mg}$, IV). Outpatient follow-up was scheduled monthly for 6 months. Long-term follow-up was performed every 2 months.

Response was classified as complete (CR) if the platelet count was $>100 \times 10^{9} / 1$, partial (PR) if platelet count $>50 \times$ $10^{9} / 1$, minimal response (MR) if platelet count was $<50 \times$ $10^{9} / 1$ and $>30 \times 10^{9} / 1$, and no response (NR) if there was no change from the baseline platelet count. Response was sustained (SR) when it was maintained for a minimum of 6 months.

Numerical variables were expressed using the median and range number. The probability to achieve more than $50 \times 10^{9} / 1$ and $100 \times 10^{9} / 1$ platelets and the median time from response to end of follow-up was calculated using the Kaplan and Meier method.

Before starting treatment, all patients signed an informed consent authorization. The procedures done in this protocol were in accordance with the Helsinki Declaration of 1975. The protocol was approved by the Ethics Committee of the participating hospitals.

\section{Results}

Eighteen patients were candidates for this therapy, and all of them were suitable for evaluation because they received the planned four doses of rituximab. Patient characteristics and response to rituximab are shown in Table 1. Median age for the whole group was 43.5 years (range, 17 to 70 ). Median platelet count at baseline was $12.5 \times 10^{9} / 1$ (range, 3.0 to 26.3). Median follow-up was 26 months (range, 12 to 59). Mean number of treatment regimens received before rituximab was 5.5 (range, 3 to 8 ). Fifteen patients (83\%) had failed to splenectomy.

CR was achieved in five patients (28\%), PR was obtained in another five (28\%), MR was seen in four $(22 \%)$ patients, and two patients were considered treatment failures (11\%). Two patients were lost to follow-up (11\%). Ten patients $(55 \%)$ achieved $>50 \times 10^{9} / 1$ platelets. Median time from the first rituximab dose to achievement of any response was 14 weeks (range, 4 to 32). Twelve patients (67\%) showed SR beyond the sixth month of follow-up. As expected from the results depicted in Table 1, we were unable to find any correlation between the ITP duration and the type of response to rituximab. Figure 1 shows the median platelet counts during follow-up in three different groups of patients classified according to their pattern of response (CR, PR, and MR). The median time to achieve $>50 \times 10^{9} / 1$ platelets was 5 months $(95 \% \mathrm{CI}=0.5$ to 11.6 months), and the median time to achieve $>100 \times 10^{9} /$ 1 platelets was not reached (Fig. 2). One patient relapsed 22 months after the first course of rituximab. She received steroids for another 14 months; she did not obtain response, and a second course of rituximab was given using the regimen described previously. She achieved a new PR 6 months after stopping therapy. After 22 months of followup, PR still remains in this patient.

Median time of response duration was 54 months (95\% CI $=15-93$ months) for patients with CR, 18 months $(95 \%$ $\mathrm{CI}=8-28$ months) for patients with partial response, and 12 months $(95 \% \mathrm{CI}=7-17$ months) for those individuals with minimal response. Difference was statistically significant between patients in $\mathrm{CR}$ vs those achieving PR or MR $(p<0.05)$. No difference was observed between PR and MR (Fig. 3). 
Table 1 Patient characteristics and outcomes

\begin{tabular}{|c|c|c|c|c|c|c|c|}
\hline $\begin{array}{l}\text { Patient/age/ } \\
\text { gender }\end{array}$ & $\begin{array}{l}\text { Evolution }^{\mathrm{a}} \\
\text { (months) }\end{array}$ & Previous treatments & $\begin{array}{l}\text { PC at baseline } \\
\left(\times 10^{9} / 1\right)\end{array}$ & $\begin{array}{l}\mathrm{PC} \text { at } 12 \text { months } \\
\left(\times 10^{9} / 1\right)\end{array}$ & $\begin{array}{l}\text { Time to response } \\
\text { (weeks) }\end{array}$ & $\begin{array}{l}\text { Response } \\
\text { type }\end{array}$ & SR \\
\hline $1 / 42 / \mathrm{F}$ & 37 & $\mathrm{P}, \mathrm{S}, \mathrm{Az}, \mathrm{D}, \mathrm{IFN}$ & 3.0 & 146 & 24 & $\mathrm{CR}$ & Yes \\
\hline $2 / 43 / \mathrm{F}$ & 84 & $\mathrm{P}, \mathrm{S}, \mathrm{Az}, \mathrm{D}, \mathrm{IFN}, \mathrm{V}$ & 5.0 & 123 & 24 & $\mathrm{CR}$ & Yes \\
\hline $3 / 30 / F$ & 48 & $\mathrm{P}, \mathrm{S}, \mathrm{Az}, \mathrm{D}, \mathrm{IFN}, \mathrm{V}$ & 12.5 & 34. 5 & 16 & MR & Yes \\
\hline $4^{\mathrm{b}} / 27 / \mathrm{F}$ & 38 & $\mathrm{P}, \mathrm{S}, \mathrm{Az}, \mathrm{D}, \mathrm{IFN}$ & 24.4 & 78 & 16 & $\mathrm{PR}^{\mathrm{b}}$ & Yes $^{\mathrm{b}}$ \\
\hline 5/70/M & 60 & $\mathrm{P}, \mathrm{Az}, \mathrm{D}, \mathrm{V}$ & 7.8 & NR & NR & NR & No \\
\hline $6 / 43 / \mathrm{F}$ & 96 & $\mathrm{P}, \mathrm{S}, \mathrm{Az}, \mathrm{D}, \mathrm{IFN}, \mathrm{V}$ & 10.1 & 37.7 & 8 & MR & Yes \\
\hline $7 / 53 / \mathrm{F}$ & 96 & $\mathrm{P}, \mathrm{S}, \mathrm{Az}, \mathrm{D}, \mathrm{IFN}, \mathrm{V}$ & 12.5 & 54 & 12 & PR & Yes \\
\hline $8 / 36 / F$ & 264 & $\begin{array}{l}\text { P, S, Az, D, IFN, V, } \\
\text { OE, IVIg }\end{array}$ & 5.0 & 30.6 & 4 & MR & Yes \\
\hline $9 / 17 / \mathrm{F}$ & 38 & $\begin{array}{l}\mathrm{P}, \mathrm{S}, \mathrm{Az}, \mathrm{D}, \mathrm{IFN}, \mathrm{V} \\
\mathrm{OE}\end{array}$ & 6.5 & 129 & 4 & $\mathrm{CR}$ & Yes \\
\hline $10 / 57 / \mathrm{F}$ & 26 & $\mathrm{P}, \mathrm{Az}, \mathrm{D}$ & 8.3 & 64 & 8 & PR & Yes \\
\hline $11 / 36 / \mathrm{F}$ & 25 & $\mathrm{P}, \mathrm{S}, \mathrm{Az}, \mathrm{D}, \mathrm{IFN}, \mathrm{V}$ & 7.0 & 49 & 20 & $\mathrm{MR}$ & No \\
\hline $12 / 63 / \mathrm{F}$ & 120 & $\mathrm{P}, \mathrm{Az}, \mathrm{D}, \mathrm{V}$ & 26.3 & NR & NR & NR & No \\
\hline $13 / 53 / \mathrm{F}$ & 348 & $\mathrm{P}, \mathrm{De}, \mathrm{D}, \mathrm{S}, \mathrm{Az}$ & 22.0 & 112 & 8 & $\mathrm{CR}$ & Yes \\
\hline $14 / 22 / \mathrm{F}$ & 266 & P, S, D, IFN, IVIg & 12.6 & 67 & 12 & PR & No \\
\hline $15 / 56 / \mathrm{F}$ & 137 & $\mathrm{P}, \mathrm{D}, \mathrm{S}, \mathrm{Az}$ & 18.4 & 223 & 4 & $\mathrm{CR}$ & Yes \\
\hline $16 / 35 / \mathrm{F}$ & 38 & $\mathrm{P}, \mathrm{D}, \mathrm{Az}, \mathrm{S}$ & 23.2 & 11.4 & 0 & NR & No \\
\hline $17 / 52 / \mathrm{F}$ & 41 & $\mathrm{P}, \mathrm{D}, \mathrm{S}$ & 16.5 & 51.9 & 4 & PR & Yes \\
\hline $18 / 24 / \mathrm{F}$ & 60 & $\mathrm{O}, \mathrm{D}, \mathrm{S}$ & 24.0 & NR & NR & NR & No \\
\hline
\end{tabular}

$P C$ Platelet count, $P$ prednisone, $S$ splenectomy, $A z$ azathioprine, $D$ danazol, $I F N$ interferon alpha $2 \mathrm{~b}, V$ vincristine, $D e$ dexamethasone, $O E$ opsonized erythrocytes

${ }^{\text {a }}$ Time from ITP diagnosis to rituximab therapy

${ }^{\mathrm{b}}$ A second course of rituximab was given

Side effects related to the first dose of rituximab such as fever, chills, and respiratory symptoms were common ( 8 out of 18 patients, 43\%). There were no severe adverse events during drug administration. Neither hemorrhagic events nor infections were recorded. Neutropenia, an occasional long-term side effect of rituximab therapy, was never recorded in our group of patients (Fig. 4). In fact, the lower neutrophil count recorded during the study was $1.3 \times$ $10^{9} / 1$ in patient 7 after 6 weeks of treatment with rituximab. No patient needed additional immunosuppressive therapy

Fig. 1 Platelet count achieved after first dose of rituximab (time 0 first dose of rituximab). Diamonds, CR; ovals, PR; triangles, MR

Type of response (mean)

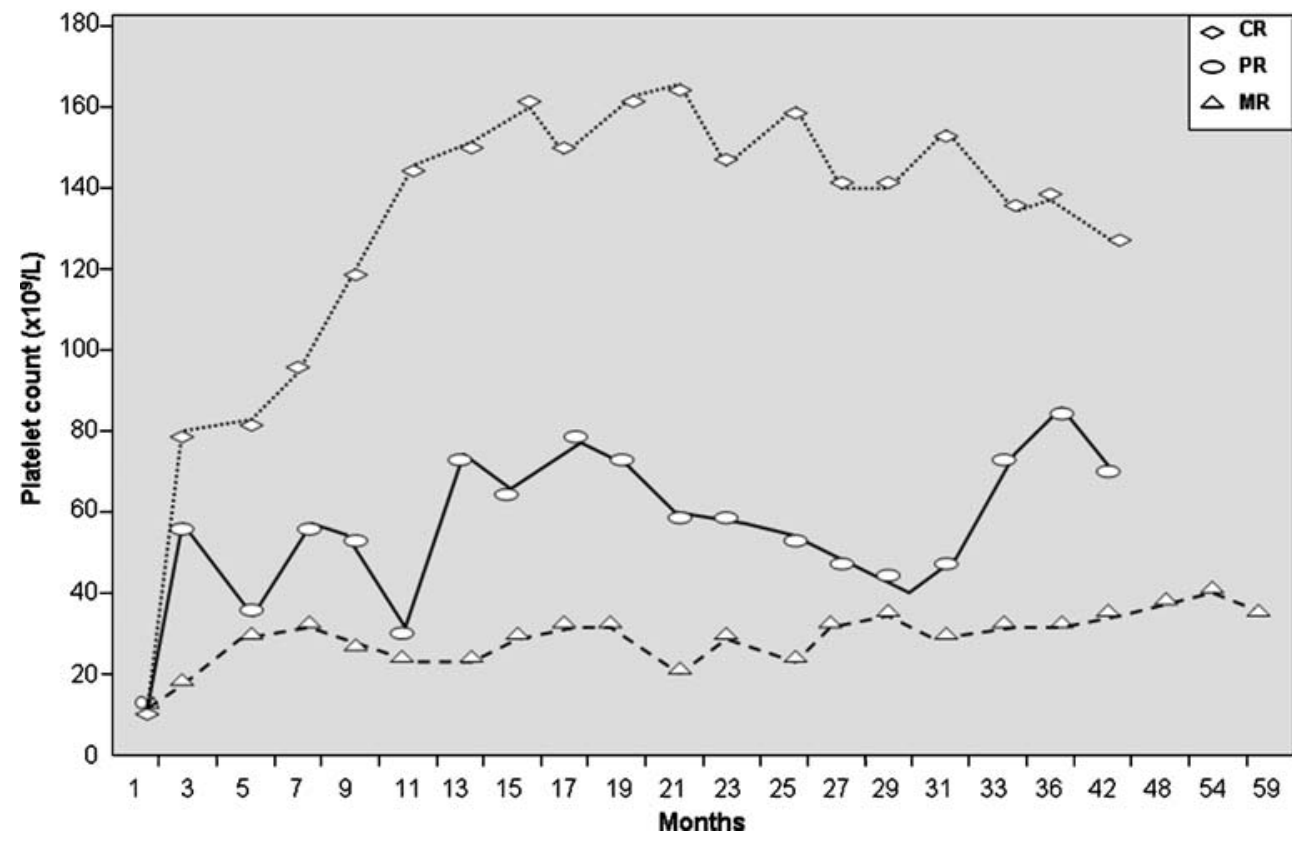




\section{a Probability to achieve $>50 \times 10^{9} / L$ platelets}

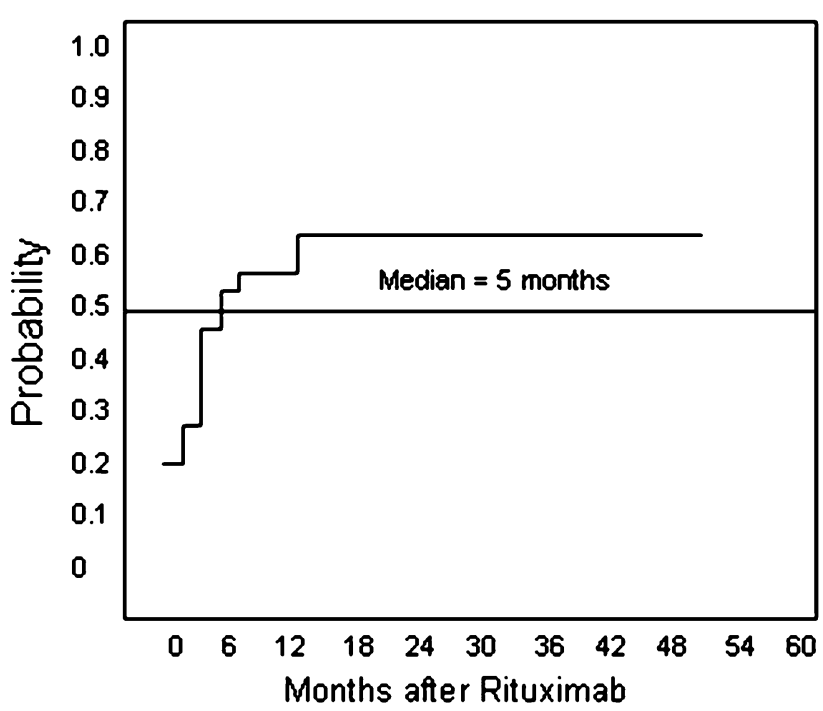

b Probability to achieve $>100 \times 10^{9} / \mathrm{L}$ platelets

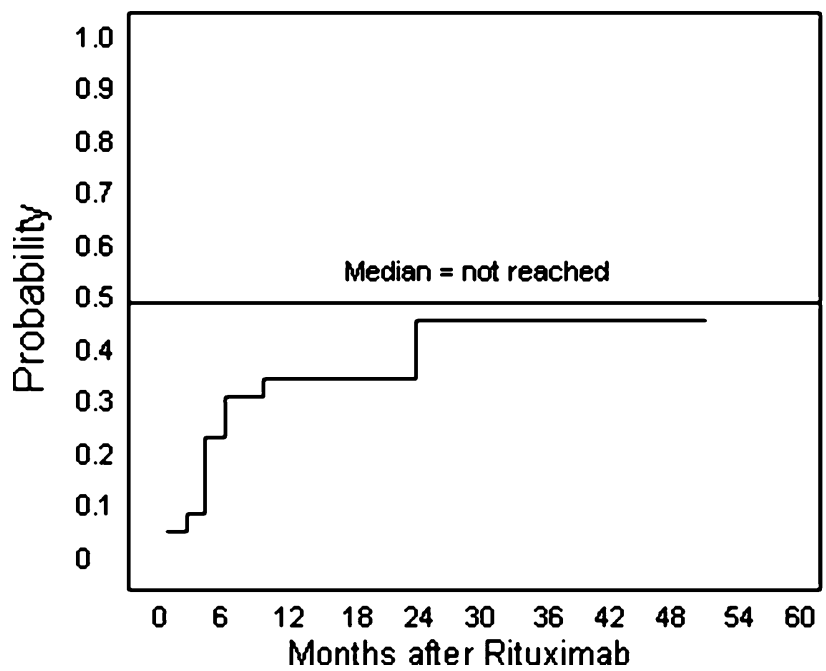

Fig. 2 Time required to obtain platelet counts $>50 \times 10^{9} / 1$ (a) or $>100 \times 10^{9} / 1$ (b) after first dose of rituximab in adult patients with chronic and refractory ITP

other than rituximab. During the whole follow-up period, no other illnesses have been recorded in this group of patients.

\section{Discussion}

Because almost $30 \%$ of individuals with ITP do not respond to the first- and second-line therapies, they live with low platelet counts, a situation that carries a high risk of hemorrhage and, eventually, a short life expectancy. It has been largely demonstrated that ITP with persistent low platelet counts carries a grave prognosis $[6,13]$. Efforts to increase the platelet count to at least $30 \times 10^{9} / 1$ include IVIg,

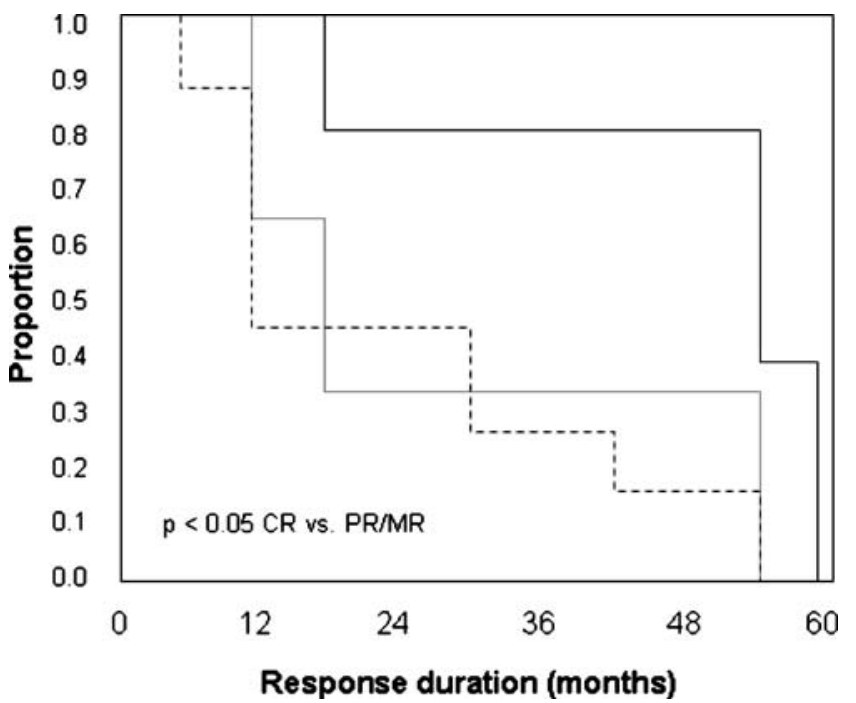

Fig. 3 Median duration of response for patients who achieved complete remission $(C R ; 54$ months, $95 \% \mathrm{CI}=15-93$ months), partial remission $(P R ; 18$ months, $95 \% \mathrm{CI}=8-28$ months $)$, or minor response ( $M R ; 12$ months, $95 \% \mathrm{CI}=7-17$ months)

anti-D immunoglobulin, cyclophosphamide, polychemotherapy such as the CHOP regimen, thrombopoietin, interleukin-11, dapsone, alpha interferon, plasma exchange, and bone marrow transplantation [23]. Using these therapies, the response rate is low and the patient is exposed to unnecessary risks [10]. When the first ITP patient successfully treated with rituximab was informed, it drew the attention of physicians because this regimen offered high response rate and low toxicity. In subsequent reports, researchers have found similar results.

The aim of this study was to evaluate the response rate achieved in 18 patients with chronic and refractory ITP after rituximab treatment as well as the evolution of these patients to learn about the possible long-term side effects associated with the use of this drug, information that is

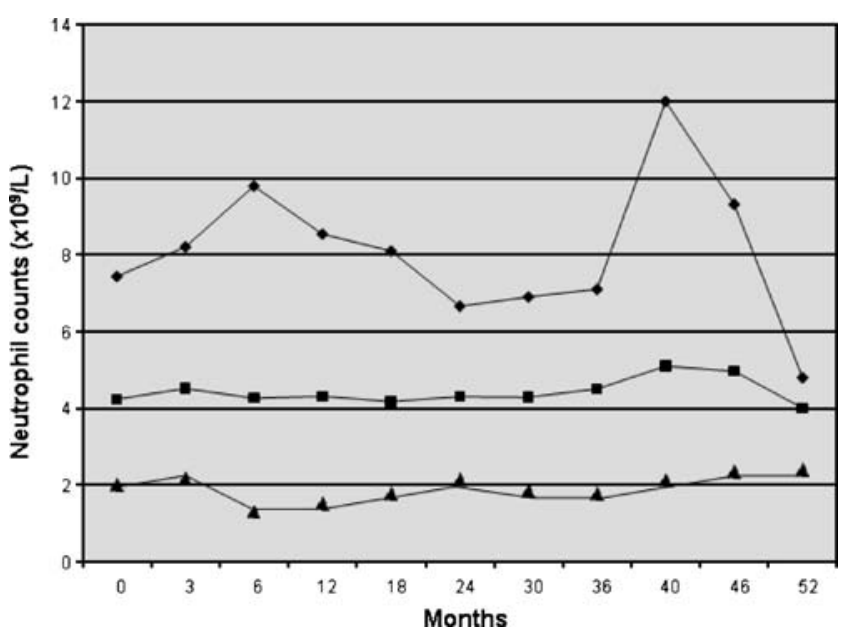

Fig. 4 Mean (squares), maximum (diamonds), and minimum (triangles) neutrophil counts through the follow-up of patients receiving rituximab for chronic and refractory ITP 
almost inexistent in the literature. We observed 12 favorable responses $(67 \%)$ and at least a stable clinical evolution in two additional patients (11\%), for a global response rate of $78 \%$. Based on the characteristics of the evolution of our group of patients, we may emphasize some points of interest: (1) Response rate obtained was quite satisfactory considering the history of chronicity and refractoriness of the patients; (2) the monoclonal antibody was well tolerated and caused only mild allergic reactions that could be easily managed with antihistaminics and paracetamol; (3) most of the patients achieve SR; and (4) increase of platelet count was not always immediate (median time to response $=14$ weeks), a fact that slightly disagrees with previous reports that found shorter time to response (3 to 8 weeks; Table 2 ) $[4,8,20]$. In fact, in a recent systematic review about the efficacy of rituximab in adult patients with ITP, it was found that median time to response was 5.5 weeks (ranges 2 to 18 weeks) [2]. We do not have an explanation for this discrepancy. After a careful analysis, we did not find significant differences between the results obtained in the systematic review and our results in terms of the variables that may affect the time to response to rituximab, namely, age, sex, previous use of corticosteroids, number of treatments before rituximab, rituximab dose and schedule, period between diagnosis and rituximab administration, duration of ITP before rituximab, and pretreatment platelet counts. Although splenectomy may not be a significant predictor of response to rituximab as previously suggested $[2,4,8]$, it should be noted that $83 \%$ of the patients included in our report had had splenectomy as compared with $50.5 \%$ of the patients in the systematic review. Therefore, history of splenectomy seems to be the only factor related to a different time to response to rituximab in our series.

Of course, we have no data about all possible variables influencing the pattern of response to rituximab. For example, we do not show information about B-cell counts and platelet autoantibodies before and after rituximab therapy, two variables that may influence the response as observed in other trials. The expected therapeutic effect of rituximab is a reduction in specific platelet-associated autoantibodies and the consequent increase in platelet counts. Although rituximab has not been always associated with a reduced load of platelet autoantibodies and most of the publications reporting this effect are small series of cases [1], the high overall response rate obtained in our study allows us to believe that rituximab effectively decreased the B-cell counts as well as the levels of platelet autoantibodies.

Three patterns of response to rituximab have been proposed: early (before the fourth dose of rituximab), intermediate ( 7 to 11 weeks after rituximab), and delayed ( $>13$ weeks after rituximab) [8]. In our study, the probability to achieve a platelet count $>50 \times 10^{9} / 1$ occurred at a median of 5 months, so we speculate that the complete inhibition of antibody formation and restoration of platelet counts with rituximab may occur after at least 5 months ( $95 \% \mathrm{CI}=0.5$ to 11.6 months) from the first dose of the antibody (Fig. 2). However, some patients may achieve a quite delayed response (as long as 1 year after therapy), a situation in which it is important to wait a reasonable time period before another treatment is planned.

A previous report informed the results obtained in patients treated with the same regimen as we used [4]. After a median follow-up of 47 weeks, the authors observed a lower overall response rate of $44 \%(C R=18 \%, P R=15 \%$, $\mathrm{MR}=10 \%$ ); most of the responses were sustained. They observed two response patterns: (1) an early-response group in which responses appeared within the first 2 weeks after the first dose of rituximab; (2) a late-response group characterized by an increase in platelets several weeks after rituximab. Finally, after a median follow-up of 72.5 weeks, the response rate was $54 \%$ with a majority of SR [8]. In a prospective trial performed in pediatric patients with chronic ITP, treatment with rituximab produced an increase of $>50 \times 10^{9} / 1$ platelets in 11 of 36 children (31\%) [3]. Median time to response was 1 week (range, 1 to 7 weeks); however, a $6 \%$ incidence of serum sickness was observed. More recently, one of the largest experiences in ITP patients treated with rituximab was published [15]. An increase of $>50 \times 10 \%$ platelets was observed in $55 \%$ of the patients $(\mathrm{CR}=46 \%, \mathrm{SR}=35 \%)$. The only predictive factor for $\mathrm{SR}$ was to achieve CR. Patients who were treated more intensively (more than three different treatments) and those with a longer ITP duration ( $>10$ years from diagnosis) had the worse response. In this study, non-splenectomized patients had a higher early response rate than those splenectomized. Although some of these results are similar
Table 2 Patterns of response in patients with chronic and refractory ITP (from $[1,6,18]$ )

$O R$ Overall response, $C R$ complete response, $P R$ partial response

\begin{tabular}{llllll}
\hline Reference & Number of patients & OR (\%) & CR (\%) & PR (\%) & Median time to response (weeks) \\
\hline Mayo clinic & 12 & 50 & 42 & 8 & $?$ \\
USA-Italy & 57 & 53 & 31 & 22 & 8 \\
Denmark & 35 & 33 & 18 & 15 & $2-8$ \\
Peru & 22 & 68 & 40 & 27 & $?$ \\
Mexico & 18 & 56 & 28 & 28 & 14 \\
\hline
\end{tabular}


to those reported in our study, we believe that contrasting results seen in our study are partially explained by differences in the inclusion and response criteria used, in the evolution time of the disease, and in the number and type of treatments given before rituximab.

As early relapses may be seen in ITP patients treated with rituximab and because re-treatment with this monoclonal antibody offers good results [16], this drug has been used as a long-term maintenance treatment. Based on longlasting remissions achieved using one or two doses of rituximab [7] and the results of late responders, we feel that a single dose of $375 \mathrm{mg} / \mathrm{m}^{2}$ every 6 months could be an alternative for this purpose.

On the other hand, because of the mechanism of action of rituximab and its interference with the immune system, we searched for possible long-term complications associated with its use, namely, neoplasias, chronic infections, or autoimmune diseases. Immune status is a major concern in patients treated with rituximab being the induction of low CD20+ counts and hypogammaglobulinemia (specifically low levels of immunoglobulin M), two previously reported secondary effects. Although we do not have data about these two immunological variables, the lack of severe infectious diseases during the long-term follow-up of our patients allows us to speculate that no severe immune abnormalities were developed in our series. As we previously stated, during the follow-up period, no associated illnesses or pathological phenomena were observed. To our knowledge, this seems to be the first report about the lack of long-term complications associated with rituximab.

In conclusion, rituximab is a long-term, safe, and effective alternative treatment of chronic and refractory ITP patients. Prospective randomized clinical trials are needed to elucidate the efficacy of the drug in comparison to splenectomy in early stages of the disease

Acknowledgment The authors declare that the treatments described in the article comply with the current law of the Mexican Republic including all ethical aspects.

\section{References}

1. Ahn ER, Bidot CJ, Fontana V, Dudkiewicz P, Jy W, Hortsman L et al (2005) Rituximab therapy induces long lasting clinical remissions and reduction of anti-platelet glycoprotein autoantibodies in patients with chronic immune thrombocytopenic purpura (ITP). Blood 6:725

2. Arnold DM, Dentali F, Crowther MA, Meyer RM, Cook RJ, Sigouin C, Fraser GA, Lim W, Kelton JG (2007) Systematic review: efficacy and safety of rituximab for adults with idiopathic thrombocytopenic purpura. Ann Intern Med 146:25-33

3. Bennett CM, Rogers ZR, Kinnamon DD, Bussel JB, Mahoney DH, Abshire TC, Sawaf H, Moore TB, Loh ML, Glader BE, McCarthy MC, Mueller BU, Olson TA, Lorenzana AN, Mentzer
WC, Buchanan GR, Feldman HA, Neufeld EJ (2006) Prospective phase $1 / 2$ study of rituximab in childhood and adolescent chronic immune thrombocytopenic purpura. Blood 107:2639-2642

4. Braendstrup P, Bjerrum OW, Nielsen OJ, Jensen BA, Clausen NT, Hansen PB, Andersen I, Schmidt K, Andersen TM, Peterslund NA, Birgens HS, Plesner T, Pedersen BB, Hasselbalch HC (2005) Rituximab chimeric anti-CD20 monoclonal antibody treatment for adult refractory idiopathic thrombocytopenic purpura. Am J Hematol 78:275-280

5. Cines DB, Blanchette VS (2002) Immune thrombocytopenic purpura. N Engl J Med 346:995-1008

6. Cohen YC, Djulbegovic B, Shamai-Lubovitz O, Mozes B (2000) The bleeding risk and natural history of idiopathic thrombocytopenic purpura in patients with persistent low platelet counts. Arch Intern Med 160:1630-1638

7. Cohen YC, Polliack A (2002) Sustained complete remission of chronic refractory immune thrombocytopenic purpura (ITP) of 10 years duration after only two infusions of rituximab. Hematol J 3:61-62

8. Cooper N, Stasi R, Cunningham-Rundles S, Feuerstein MA, Leonard JP, Amadori S, Bussel JB (2004) The efficacy and safety of B-cell depletion with anti-CD20 monoclonal antibody in adults with chronic immune thrombocytopenic purpura. Br J Haematol 125:232-239

9. Koulova L, Alexandrescu D, Dutcher JP, O’Boyle KP, Eapen S, Wiernik PH (2005) Rituximab for the treatment of refractory idiopathic thrombocytopenic purpura (ITP) and thrombotic thrombocytopenic purpura (TTP): report of three cases. Am J Hematol 78:49-54

10. Kumar S, Diehn FE, Gertz MA, Tefferi A (2002) Splenectomy for immune thrombocytopenic purpura: long term results and treatment of postsplenectomy relapse. Ann Hematol 81:312-319

11. McMillan R (1997) Therapy for adults with refractory chronic autoimmune thrombocytopenic purpura. Ann Intern Med 126:307-314

12. McMillan R (2002) Classical management of refractory adult immune (idiopathic) thrombocytopenic purpura. Blood Rev 16:51-55

13. McMillan R, Durette C (2004) Long-term outcomes in adults with chronic ITP after splenectomy failure. Blood 104:956-960

14. Passweg JR (2004) Haematopoietic stem cell transplantation for immune thrombopenia and other refractory autoimmune cytopenias. Best Pract Res Clin Haematol 7:305-315

15. Penalver FJ, Jimenez-Yuste V, Almagro M, Alvarez-Larran A, Rodriguez L, Casado M, Gallur L, Giraldo P, Hernandez R, Menor D, Rodriguez MJ, Caballero D, Gonzalez R, Mayans J, Millan I, Cabrera JR (2006) On behalf of the Multi-institutional Retrospective Spanish Study on the use of rituximab in refractory ITP. Rituximab in the management of chronic immune thrombocytopenic purpura: an effective and safe therapeutic alternative in refractory patients. Ann Hematol 85:400-406

16. Perrotta AL (2006) Re-treatment of chronic idiopathic thrombocytopenic purpura with rituximab: literature review. Clin Appl Thromb Hemost 12:97-100

17. Picozzi VJ, Roeske WR, Creger WP (1980) Fate of therapy failures in adult idiopathic thrombocytopenic purpura. Am J Med 69:690-694

18. Raj K, Narayanan S, Augustson B, Ho A, Mehta P, Duncan N, Tauro S, Mahendra P, Craddock C, Mufti G (2005) Rituximab is effective in the management of refractory autoimmune cytopenias occurring after allogenic stem cell transplantation. Bone Marrow Transplant 35:299-301

19. Reff ME, Carner K, Chambers KS, Chinn PC, Leonard JE, Raab R, Newman RA, Hanna N, Anderson DR (1994) Depletion on B cells in vivo by a chimeric mouse human monoclonal antibody to CD20. Blood 83:435-445 
20. Shanafelt TD, Madueme HL, Wolf RC, Tefferi A (2003) Rituximab for immune cytopenias in adults: idiopathic thrombocytopenic purpura, autoimmune hemolytic anemia, and Evans syndrome. Mayo Clin Proc 78:1340-1346

21. Stasi R, Pagano A, Stipa E, Amadori S (2001) Rituximab chimeric anrti-CD20 monoclonal antibody treatment for adults with chronic idiopathic thrombocytopenic purpura. Blood 98:952-957
22. Tanai C, Iki S, Nakahara F, Iijima K, Usuki K, Kuwana M, Urabe A (2004) Effective treatment with rituximab in a patient with refractory idiopathic thrombocytopenic purpura. Rinsho Kuetsueki 45:1181-1186

23. Yang R, Han ZCh (2000) Pathogenesis and management of chronic idiopathic thrombocytopenic purpura: an update. Int $\mathrm{J}$ Hematol 71:18-24 